\title{
Investigation on the Effects of Brain Retraction on Local Cerebral Metabolism Utilizing Microdialysis
}

\author{
Rigen Wu, Zhiqiang Kang* \\ Department of Pharmacy, Affiliated Hospital of Inner Mongolia Medical University, Hohhot, China \\ Email address: \\ Kangzhiliang20160104@163.com (Zhiqiang Kang) \\ ${ }^{*}$ Corresponding author
}

\section{To cite this article:}

Rigen Wu, Zhiqiang Kang. Investigation on the Effects of Brain Retraction on Local Cerebral Metabolism Utilizing Microdialysis. Clinical Medicine Research. Vol. 5, No. 4, 2016, pp. 77-81. doi: 10.11648/j.cmr.20160504.13

Received: February 17, 2016; Accepted: March 12, 2016; Published: June 15, 2016

\begin{abstract}
In order to study the effect of brain retraction on local biochemical metabolism in brain tissue and to investigate the potential application of microdialysis in monitoring local cerebral metabolic and biochemical variations owing to brain retraction injury. Brain tissues were retracted based on different retraction pressures $(30 \mathrm{mmHg}, 40 \mathrm{mmHg}, 50 \mathrm{mmHg})$ and retraction modes (intermittent and continuous tractions). Microdialysis was utilized for the dynamic collection of the dialysis fluid of extracellular fluid $(\mathrm{ECF})$, and $[\mathrm{Glu}] \mathrm{d},[\mathrm{Lac}] \mathrm{d},[\mathrm{Gly}] \mathrm{d},[\mathrm{Gluta}] \mathrm{d}$ and L/P changes were observed. Different brain retraction pressures led to the changes of [Glu]d, [Lac]d, [Gly]d, [Gluta]d and L/P to various extents in ECF. Differences between the retraction group and control group before and after injury were significantly different $(\mathrm{P}<0.05)$. A higher retraction pressure resulted in a more significant change. Continuous retraction led to more serious brain damage than intermittent retraction. [Glu]d, [Lac]d, [Gly]d, [Gluta]d and L/P of the continuous retraction group changed more apparently, and the differences between the groups were significantly different $(\mathrm{P}<005)$. Microdialysis technique is ideal for the dynamic monitoring of local biochemical changed in brain tissues resulted from brain injury, which can be utilized as a valuable tool in monitoring brain retraction injury during neurosurgical operations.
\end{abstract}

Keywords: Brain Retractor, Brain Retraction, Lactic Acid, Glycerol, Biochemical Metabolism, Microdialysis

\section{Introduction}

Retraction of brain tissues is necessary in order to obtain suitable exposure during neurosurgical operations. However, brain retractor produces pressure on brain surface that leads to the secondary injury of brain tissues. Brain retraction injury (BRI) is not only induced by the transformation of local brain issues by the brain retractor that triggers the decrease or cease of local brain tissue perfusion, but also results from the direct damage of the brain retractor that leads to cerebral infarction or delayed intracerebral hematoma and cerebral contusion [1, 2]. Various intraoperative monitoring approaches, including brain electrical activity monitoring, local cerebral blood flow and brain retraction pressure monitoring, are crucial to prevent or decrease the opportunity of secondary brain injury. As a newly developed biochemical sampling technique, microdialysis can continuously measure the concentration of biochemical substance in the ECF of living cells conveniently with tiny tissue damage, which is more close to the physiological condition than other methods and provides a novel method for the research on the pathological and physiological changes of brain injury [3]. In this paper, microdialysis technique was utilized to perform the microdialysis monitoring of local brain interstitial fluid after brain retraction to investigate the changes and corresponding principles of local brain tissue metabolism after brain retraction.

\section{Materials and Methods}

\subsection{Experimental Animals and Grouping}

Twenty ordinary adult mongrel dogs with the body weight of approximately $15 \mathrm{~kg}$ and ages among 1.5-2.0 years old (half male and half female) were bought from the experimental animal center of Inner Mongolia University of Science and Technology. The dogs were randomly grouped (5 dogs for 
each trial group and the control group) according to different retraction pressures $(30 \mathrm{mmHg}, 40 \mathrm{mmHg}, 50 \mathrm{mmHg}$ ) and retraction modes (intermittent and continuous tractions). Each dog was treated by opening cranium on both sides and inserting probes without brain retraction. Their brain interstitial fluids were collected for microdialysis, which were used as the control for those of the retraction group.

\subsection{Microdialysis Methods}

Microdialysis equipment was provided by CMA Co. (Sweden), including microdialysis catheter, micro-injection pimp, micro-sampling bottle, micro-syringe and microdialyzer. Length and external diameter of the microdialysis tube membrane were $2 \mathrm{~mm}$ and $0.5 \mathrm{~mm}$, respectively. Perfusion microdialysis Ringe solution specific for micro-perfusion was filtered by a $0.2 \mu \mathrm{L}$ micropore filter paper. Temperature and rate of the perfusion solution during microdialysis were maintained at $360-38.0^{\circ} \mathrm{C}$ and $2 \mu \mathrm{L} / \mathrm{min}$, respectively.

Experiments of different retraction pressures: Pressure sensor of the intracranial pressure monitor was fixed in the front of a $1.5 \mathrm{~cm}$ wide brain retractor. $30 \mathrm{mmHg}, 40 \mathrm{mmHg}$ and $50 \mathrm{mmHg}$ retraction pressure were used to retract the right temporal lobe brain tissue. Microdialysis catheter was inserted into the brain tissue below the brain retractor according to relevant operation guideline preventing bone spurs from damaging the microdialysis membrane. Insert depth was restricted by the entire entrance of bone hole of the whit part of the membrane to ensure that the membrane was totally inserted into the brain tissue and microdialysis was sufficient. $2.5 \mathrm{~mL}$ of dialysis fluid was collected by a specific hollow needle, which was connected with to the microdialysis catheter after evacuation. Then the needle filled with dialysis fluid was placed in a micro-injection pump for bolus injection with the rate of $2 \mu \mathrm{L} / \mathrm{min}$. Samples were collected every half hour in $5 \mathrm{~h}$ (samples collected within the first $1 \mathrm{~h}$ were discarded) [4].

Experiments of different retraction modes: Brain tissues were retracted by a $2 \mathrm{~cm}$ wide brain retractor and $50 \mathrm{mmHg}$ pressure utilizing continuous mode $(2 \mathrm{~h})$ and intermittent mode (distal end of the brain retractor was fixed at a self-sustained brain retractor fixator, temporal lobe was retracted for 8 times in $2 \mathrm{~h}$, each time $15 \mathrm{~min}$, intermittent time $5 \mathrm{~min}$ ). Microdialysis was performed with a same operation procedure. Dialysis fluid was collected every $15 \mathrm{~min}$ in $2 \mathrm{~h}$, which was intermediately stored in a $-20^{\circ} \mathrm{C}$ refrigerator to prevent active substances from damage for further analysis.

Bone windows were cut on both sided of each dog, and microdialysis probe was inserted after cutting off the dura mater without retracting brain tissues, which was utilized as the control [5].

\subsection{Biochemical Analysis}

CMA600 microdialyzer and relevant kits were utilized to analyze the contents of glucose (Glu), lactic acid (Lac), pyruvic acid (Pyr), glycerol (Gly) and glutamic acid (Gluta), and Lac/Pry ratio was calculated.

\subsection{Statistical Analysis}

All the data were expressed as mean \pm standard deviation $(\mathrm{x} \pm \mathrm{s})$. SAS9.1 statistical software was utilized to perform variance analysis and $\mathrm{q}$ test, etc., $\mathrm{P}<0.05$ was considered statistically significant.

\section{Results}

\subsection{Effects of Different Brain Retraction Pressures on Local Cerebral Metabolism}

Insertion of microdialysis catheter slightly changed [Glu]d, [Lac]d, [Gly]d, [Gluta]d and L/P ratio with relatively smooth curves $(\mathrm{P}>0.05)$, and the above values of each group before retraction did not differ from those of the control group $(\mathrm{P}>0.05)$. After brain tissues were retracted by different retraction pressures, [Glu]d decreased whereas [Lac]d, [Gly]d, [Gluta]d and L/P ratio increased apparently with increasing pressure. Each retraction group and the control group before and after retraction all exhibited significant differences $(\mathrm{P}<0.05)$. Concentrations of metabolism substances in ECF of the retraction and control groups are shown in Table 1.

Table 1. Concentrations of metabolism substances in ECF of the retraction and control groups ( $X \pm s)$.

\begin{tabular}{|c|c|c|c|c|c|c|c|}
\hline Group & $\mathbf{n}$ & Retract Time (min) & $\begin{array}{l}{[\mathrm{Glu}]} \\
(\mathrm{mmol} / \mathrm{L})\end{array}$ & $\begin{array}{l}\text { [Lac] } \\
(\mathrm{mmol} / \mathrm{L})\end{array}$ & $\begin{array}{l}\text { [Gly] } \\
(\mu \mathrm{mol} / \mathrm{L})\end{array}$ & $\begin{array}{l}\text { [Gluta] } \\
(\mu \mathrm{mol} / \mathrm{L})\end{array}$ & $\mathrm{L} / \mathrm{P}(\boldsymbol{\mu \mathrm { mol }} / \mu \mathrm{mol})$ \\
\hline Control group & 5 & 0 & $1.82 \pm 0.41$ & $2.01 \pm 0.32$ & $33.21 \pm 2.78$ & $7.72 \pm 1.01$ & $24.15 \pm 2.28$ \\
\hline $30 \mathrm{mgHg}$ Group & 5 & 300 & $1.34 \pm 0.12 *$ & $4.03 \pm 0.15^{*}$ & $48.22 \pm 5.33 *$ & $18.56 \pm 2.04 *$ & $43.56 \pm 3.81 *$ \\
\hline 40mgHg Group & 5 & 300 & $0.75 \pm 0.20 *$ & $4.96 \pm 0.25 *$ & $70.14 \pm 4.18^{*}$ & $28.47 \pm 1.26^{*}$ & $53.17 \pm 1.84 *$ \\
\hline $50 \mathrm{mgHg}$ Group & 5 & 300 & $0.68 \pm 0.21 *$ & $6.33 \pm 2.21 *$ & $85.77 \pm 9.14^{*}$ & $36.82 \pm 3.34 *$ & $60.55 \pm 2.69 *$ \\
\hline
\end{tabular}

Compared with Control group, ${ }^{*} \mathrm{P}<\mathrm{O} .05$.

\subsection{Effects of Different Brain Retraction Modes on Local Cerebral Metabolism}

Insertion of microdialysis catheter slightly changed [Glu]d, [Lac]d, [Gly]d, [Gluta]d and L/P ratio with relatively smooth curves $(\mathrm{P}>0.05)$, and the above values of each group before retraction did not differ from those of the control group $(\mathrm{P}>0.05)$. After brain tissues were retracted by different retraction pressures, [Glu]d in ECF after intermittent and continuous retractions reduced slightly and obviously, respectively. [Glu]d, [Lac]d, [Gly]d, [Gluta]d and L/P ratio all increased to various extents after continuous retraction, which were more apparent than those after intermittent retraction. Results of the two groups showed significant differences $(\mathrm{P}<0.05)$, and the results are listed in Table 2 . 
Table 2. Effects of different brain retraction modes on local cerebral metabolism ( $X \pm s)$.

\begin{tabular}{llllllll}
\hline Group & $\mathbf{n}$ & $\begin{array}{l}\text { Retract Time } \\
(\mathbf{m i n})\end{array}$ & $\begin{array}{l}{[\mathbf{G l u}]} \\
(\mathbf{m m o l} / \mathbf{L})\end{array}$ & $\begin{array}{l}{[\mathbf{L a c}]} \\
(\mathbf{m m o l} / \mathbf{L})\end{array}$ & $\begin{array}{l}{[\mathbf{G l y}]} \\
(\boldsymbol{\mu m o l} / \mathbf{L})\end{array}$ & $\begin{array}{l}{[\mathbf{G l u t a}]} \\
(\boldsymbol{\mu m o l} / \mathbf{L})\end{array}$ & $\begin{array}{l}\mathbf{L} / \mathbf{P} \mathbf{~ r a t i o} \\
(\boldsymbol{\mu m o l} / \boldsymbol{\mu m o l})\end{array}$ \\
\hline Control group & 5 & 0 & $1.82 \pm 0.41$ & $2.01 \pm 0.32$ & $33.21 \pm 2.78$ & $7.72 \pm 1.01$ & $24.15 \pm 2.28$ \\
Intermittent retraction Group & 5 & 120 & $1.54 \pm 1.36^{*}$ & $3.36 \pm 0.25^{*}$ & $45.17 \pm 2.16^{*}$ & $16.08 \pm 1.31^{*}$ & $37.89 \pm 2.41^{*}$ \\
continuous retraction Group & 5 & 120 & $1.05 \pm 0.22^{*}$ & $6.03 \pm 1.47^{*}$ & $66.65 \pm 3.02^{*}$ & $25.81 \pm 1.13^{*}$ & $48.39 \pm 2.58^{*}$ \\
\hline
\end{tabular}

Compared with Control group, ${ }^{*} \mathrm{P}<0.05$

\section{Discussion}

Andrews proposed the concept of BRI in 1994 for the first time, referring to sufficient revealing of surgical fields in craniotomies and local cerebral lobe contusion, edema, ischemia and further local hematoma or cerebral infarction owing to undue retraction of brain tissues [6]. Meanwhile, skull base surgeries targeting deep lesions including cerebellopontine angle area, saddle area, slope, brainstem, etc. that are surrounded by important neurovascular structures are lack of enough surgical fields [7]. Therefore, BRI occurs much more frequently in skull base surgeries than that in other common brain surgeries. BRI is induced by brain retraction in about $10 \%$ of skull base tumors, $5 \%$ of intracranial aneurysms and other intracranial tumor surgeries. BRI is induced not only by the decrease or cease of local cerebral perfusion due to deformation of local brain tissues retracted by brain retractor, but also by the direct retraction injury due to the retractor [8]. As a result, cerebral infarction or delayed intracerebral hematoma and cerebral contusion are triggered. Number and shape of brain retractor as well as intensity, time and mode of retraction are directly associated with the nature of BRI.

\subsection{Effects of Brain Retraction Pressure on Brain Tissue Metabolism}

$20 \mathrm{mmHg}, 30 \mathrm{mmHg}$ and $40 \mathrm{mHg}$ retraction pressures were used to retract brain tissues in this study. [Glu]d, [Lac]d, [Gly]d, [Gluta]d and L/P ratio in local ECF dialysis fluid all changed to various extents, which changed increasingly apparently with increasing retraction pressure. After $30 \mathrm{~min}$ of $40 \mathrm{mmHg}$ retraction, [Glu]d began to decrease, whereas [Lac]d, [Gly]d, [Gluta]d and L/P ratio began to increase, leading to serious brain damages. $30 \mathrm{mmHg}$ and $20 \mathrm{mmHg}$ retractions resulted in relatively serious and slight brain injuries, respectively. Bennett et al. retracted the temporal lobes of dogs for $1 \mathrm{~h}$ with the pressure of $25 \mathrm{mmHg}$, leading to the damage of blood brain barrier [9]. The dogs were killed after continuously recording their somatosensory evoked potentials (SSEP) for $24 \mathrm{~h}$ and retracting for $72 \mathrm{~h}$, and cerebral edema was then found in histopathology study. They also investigated the retraction effects of lower than $50 \mathrm{mmHg}$ pressure continuously used in $1 \mathrm{~h}$ and the induced low pressure effects. SSEP amplitude of the normal group at the pressure $<30 \mathrm{mmHg}$ was higher than $80 \%$ of the normal value, whereas SSEP amplitude was less than $60 \%$ of the normal one at the pressure $>40 \mathrm{mmHg}[10]$.

Increase of brain retraction pressure (BRP) mainly contributes to local low perfusion, which leads to vascular occlusion and predominately. As a result, veins are firstly influenced owing to the lack of flexibility $[11,12]$. Besides, a higher pressure will also induce arterial occlusion, and thus the pressure is transferred to the adjacent vessels, thereby reducing the brain electrical activity relying on diastolic pressure. This is one of the mechanisms damaging nervous tissues due to primary and secondary local edema.

\subsection{Effects of Brain Retraction Modes on Brain Tissues}

Brain retraction modes are divided into continuous and intermittent brain retractions. Continuous brain retraction refers to a continuous retraction for more than $1 \mathrm{~h}$, and intermittent brain retraction refers to repeated retraction and relaxation within $1 \mathrm{~h}$. In this study, continuous retraction was conducted for $2 \mathrm{~h}$, and intermittent retraction was performed for $15 \mathrm{~min}$ with $5 \mathrm{~min}$ of intermittence that was repeated for 8 times in $2 \mathrm{~h}$. Continuous retraction induced severe damages in the apparent changes of [Glu]d, [Lac]d, [Gly]d, [Gluta]d and $\mathrm{L} / \mathrm{P}$ ratio, whereas intermittent retraction slightly affected the values and resulted in slight injuries. Yokoh et al [13]. compared the results of intermittent and continuous retractions utilizing a dog BRI model, in which continuous retraction was conducted for $60 \mathrm{~min}$, and intermittent retraction was performed for $10 \mathrm{~min}$ with $5 \mathrm{~min}$ of intermittence that was repeated for 6 times in $60 \mathrm{~min}$. Threshold values of totally recovered electrocorticograms for continuous and intermittent retraction groups ranged among 30-40 g and 40-50 g, respectively. A $40 \mathrm{~g}$ intermittent retraction pressure damaged $\mathrm{BBB}$ much less obviously than a $30 \mathrm{~g}$ continuous retraction pressure, and an additional $20 \mathrm{~g}$ of intermittent retraction pressure was in need to trigger the same extent of brain injury as continuous retraction did. Intermittent retraction outweighs continuous one owing to a transient re-perfusion in brain tissues every $0-15 \mathrm{~min}$. A vascular occlusion global ischemia model has verified that an optimal cycle for the re-perfusion time interval after ischemia is determinant. Intervals between ischemia during intermittent retraction are commonly $5 \mathrm{~min}$ or even less, which results in much less damages in brain compared to longer re-perfusion periods. Recently, a local ischemia animal model due to temporary blocking of arteries has revealed that intermittent ischemia accompanied by repeated re-perfusions were more conductive to brain tissues than continuous ischemia $[14,15]$.

\subsection{Brain Microdialysis Monitor}

Biochemical studies of brain injury is important among neuroscience research, which have been commonly performed 
by analyzing biochemical substance contents in brain homogenates and cerebrospinal fluids [16]. However, these methods cannot directly reflect the dynamic variations of biochemical substances in living ECF, thereby limiting the research on the direct survival microenvironment of brain cells. Brain microdialysis technique, which bases on the diffusion principle of small molecules in the movement along concentration gradient through a semipermeable membrane, is able to continuously detect biochemical substance levels in injured local ECF before and after living brain injuries dynamically and reflect the changes of extracellular microenvironment and brain function metabolism. This technique has been used in the studies on glucose and lactate changes in brain cell ECF of animal models in the conditions of physiological state, cerebral ischemia and subarachnoid hemorrhage. Glucose mainly provides energy in brain tissues, thus their abnormal energy metabolism mainly refers to abnormal glucose metabolism [17].

Brain retraction leads to incomplete cerebral ischemia, hypoxia, decreased glucose utilization, aerobic oxidation obstacle and enhanced glycolysis in local brain tissues, which thus result in reduced glucose concentration, decreased pyruvate production and increased lactate production in brain tissues. In the presence of further ischemia and hypoxia, excitatory amino acids such as glutamate aggregate, and cell membrane degrades, thereby releasing glycerol [18]. Glucose concentrations of each retraction group herein all decreased to different extents, whereas those of lactate, pyruvate, glycerol and glutamate all increased to various extents during different time periods. The results indicate that local brain tissues exhibited ischemia after brain retraction, and a higher retraction pressure led to a more severe ischemia. Cerebral ischemic injury induced by continuous retraction was much more serious compared to that induced by intermittent traction $[19,20]$.

\section{Conclusion}

Microdialysis technique is a minimally invasive, safe, novel monitor strategy, which is able to both continuously and dynamically monitor the contents of local biochemical substances after brain retraction. Besides, it can also be used as a valuable tool for monitoring retraction brain injury in neurosurgeries.

\section{References}

[1] Badr AE, Yin W, Mychaskiw G, Zhang JH. Effect of hyperbaric oxygen on striatal metabolites: a microdialysis study in awake freely moving rats after MCA occlusion. Brain Res 2001, 916: 85-90.

[2] McClelland HM. Retraction of "Celik S., Aksoy G., Akyolcu N (2004) Nursing role on preventing secondary brain injury. Accident \& Emergency Nursing, 12(2), 94-98". Accid Emerg Nurs 2007, 15: 72 .

[3] Maurer MH. Proteomics of brain extracellular fluid (ECF) and cerebrospinal fluid (CSF). Mass Spectrom Rev 2010, 29: 17-28.
[4] $\mathrm{Xu} \mathrm{W,} \mathrm{Mellergard} \mathrm{P,} \mathrm{Ungerstedt} \mathrm{U,} \mathrm{Nordstrom} \mathrm{CH.} \mathrm{Local}$ changes in cerebral energy metabolism due to brain retraction during routine neurosurgical procedures. Acta Neurochir (Wien) 2002, 144: 679-683.

[5] Lorenz MW, Thoelen N, Loesel N, Lienerth C, Gonzalez M, Humpich M, et al. Assessment of cerebral autoregulation with transcranial Doppler sonography in poor bone windows using constant infusion of an ultrasound contrast agent. Ultrasound Med Biol 2008, 34: 345-353.

[6] Wise BL. A review of brain retraction and recommendations for minimizing intraoperative brain injury. Neurosurgery 1994, 35: 172-173.

[7] Andrews RJ, Bringas JR. A review of brain retraction and recommendations for minimizing intraoperative brain injury. Neurosurgery 1993, 33: 1052-1063; discussion 1063-1054.

[8] Zhong J, Dujovny M, Perlin AR, Perez-Arjona E, Park HK, Diaz FG. Brain retraction injury. Neurol Res 2003, 25: 831-838.

[9] Bennett MH, Albin MS, Bunegin L, Dujovny M, Hellstrom H, Jannetta PJ. Evoked potential changes during brain retraction in dogs. Stroke 1977, 8: 487-492.

[10] Uno J, Kuwabara S, Fukuda M, Ishikawa S. [Experimental study of brain stem infarction in dogs--effect on BAEP, SSEP, blink reflex and EEG of perforator occlusion]. No To Shinkei 1988, 40: 993-999.

[11] Lubnin A, Luk'ianov VI, Salalykin VI, Makhmudov UB. [The retraction pressure during neurosurgical operations on the brain. III. An analysis of the efficacy of prophylactic methods aimed at reducing brain volume]. Zh Vopr Neirokhir Im N N Burdenko 1995: 21-25.

[12] Lubnin A, Korshunov AG, Sazonova OB, Goriachev AS, Salalykin VI, Makhmudov UB. [The retraction pressure in neurosurgical operations on the brain. II. An analysis of the complications related to the use of retractors]. Zh Vopr Neirokhir Im N N Burdenko 1995: 20-22.

[13] Yokoh A, Sugita K, Kobayashi S. Intermittent versus continuous brain retraction. An experimental study. $J$ Neurosurg 1983, 58: 918-923.

[14] Bittigau P, Sifringer M, Felderhoff-Mueser U, Hansen HH, Ikonomidou C. Neuropathological and biochemical features of traumatic injury in the developing brain. Neurotox Res 2003, 5: 475-490.

[15] Wu ZJ, Cai RL, Long DH, He L, Hu L. [Effects of electroacupuncture of "Shenmen" (HT 7) and "Taixi" (KI 3) on cardiac sympathetic activities in acute myocardial ischemia rabbits]. Zhen Ci Yan Jiu 2010, 35: 32-36.

[16] Chatzipanteli K, Alonso OF, Kraydieh S, Dietrich WD. Importance of posttraumatic hypothermia and hyperthermia on the inflammatory response after fluid percussion brain injury: biochemical and immunocytochemical studies. J Cereb Blood Flow Metab 2000, 20: 531-542.

[17] Halperin JA, Martin AM, Malave S. Increased digitalis-like activity in human cerebrospinal fluid after expansion of the extracellular fluid volume. Life Sci 1985, 37: 561-566.

[18] Clow KA, Ewart KV, Driedzic WR. Low temperature directly activates the initial glycerol antifreeze response in isolated rainbow smelt (Osmerus mordax) liver cells. Am J Physiol Regul Integr Comp Physiol 2008, 295: R961-970. 
[19] Retraction notice to "the protective mechanism of progesterone on blood-brain barrier in cerebral ischemia in rats" Brain Research Bulletin 79 (2009) 426-430. Brain Res Bull 2010, 81: 524.
[20] Zhong J, Dujovny M, Perlin AR, Perez-Arjona E, Park HK, Diaz FG. Brain retraction injury. Neurol Res 2003, 25: 831-838. 